\title{
SOCS3 is epigenetically up-regulated in steroid resistant nephrotic children
}

\author{
Katarzyna Zaorska ${ }^{1 凶}$, Piotr Zawierucha², Danuta Ostalska-Nowicka ${ }^{3}$ and Michał Nowicki ${ }^{1}$ \\ 'Department of Histology and Embryology, Poznan University of Medical Sciences, Poznań, Poland; ²Department of Anatomy, Poznan University \\ of Medical Sciences, Poznań, Poland; ${ }^{3}$ Clinic of Cardiology and Nephrology, Poznan University of Medical Sciences, Poznań, Poland
}

\begin{abstract}
Background. The mechanism of steroid resistance in children with the nephrotic syndrome is yet unknown. About $20 \%$ of patients demonstrate steroid unresponsiveness and progress to end stage renal disease. Aberrant SOCS3 and SOCS5 expression in steroid resistant and sensitive patients has previously been demonstrated. Here, we investigate genetic and epigenetic mechanisms of regulation of SOCS3 and SOCS5 transcription in nephrotic children. Methods. 76 patients with the nephrotic syndrome (40 steroid resistant and 36 steroid sensitive) and 33 matched controls were included in this study. We performed genotyping of a total of 34 single nucleotide polymorphisms for SOCS3 and SOCS5 promoters and evaluated their methylation status using MS-PCR and QMSP methods. Results. Steroid resistant patients had a significantly lower methylation of one region of SOCS3 promoter in comparison with steroid sensitive patients and controls $(p<0.0001)$. However, the relative methylation level in the steroid sensitive patients and controls differed significantly even before the first steroid dose $(p=0.001758)$. Other SOCS3 and SOCS5 promoter regions displayed no differences in methylation or were fully methylated/unmethylated in all study groups, showing site-specific methylation. The allele and genotype distribution for SOCS3 and SOCS5 markers did not differ statistically between the groups. Conclusions. We demonstrate an epigenetic mechanism of SOCS3 upregulation in steroid resistant children with the nephrotic syndrome. The assessment of methylation/unmethylation of SOCS3 promoter might be an early marker for steroid responsiveness in NS patients.
\end{abstract}

Key words: methylation, nephrotic syndrome, single nucleotide polymorphism, steroid resistance

Received: 09 July, 2015; revised: 18 November, 2015; accepted: 18 December, 2015; available on-line: 01 February, 2016

\section{INTRODUCTION}

Idiopathic nephrotic syndrome (INS) in children is characterized by massive proteinuria and generalized oedema (Bagga \& Mantan, 2005). Its incidence is estimated at 2-7/100 000 annually and depends on age, gender and ethnicity (Holt \&Webb, 2002). A wide spectrum of histopathological features has been described in biopsy specimens from nephrotic patients and the pathogenesis is most often attributed to abnormalities in the immune responses and aberrant cytokine signaling, including the Jak/Stat pathway defects, leading to chronic inflammation and renal fibrosis (Gómez-Guerro et al., 2004; Huang et al., 2008; Thomas, 2009). Manage- ment of nephrotic patients is based on oral glucocorticosteroids (GCs). Patients typically respond to the steroid treatment, although they often require prolonged or alternative therapy due to recurrent relapses, steroid dependence or side effects. Still, up to $20 \%$ of patients manifest steroid unresponsiveness and are at a particular risk of high doses of steroids and rapid progression to end stage renal disease (Holt \& Webb, 2002; Bagga \& Mantan, 2005). Numerous studies have been conducted to reveal the mechanism of steroid resistance and to determine its early biomarkers. Several factors, including gene mutations and polymorphisms, have been attributed to steroid unresponsiveness, however, the pathophysiology of INS and the mechanisms of steroid resistance still remain to be elucidated (Hinkes et al., 2008, Jafar et al., 2011).

Our previous study demonstrated significant up-regulation of SOCS3 and SOCS5 in steroid resistant nephrotic patients when compared to steroid sensitive patients and normal controls (Ostalska-Nowicka et al., 2011). Numerous diseases have been attributed to immunological perturbations and abnormal SOCS inhibitors activity, particularly their anti-inflammatory and tumor suppressor functions have been implicated in a variety of inflammatory conditions and cancers (Delcuve et al., 2009; Zhang et al., 2009). Gene expression and mechanisms of promoter regulation have been studied extensively. Recently, it has been reported that gene promoters may be actively methylated and demethylated (Metivier et al., 2008). Although the epigenetic mechanisms seem to be of the greatest importance for the regulation of gene transcription, genetic alterations in the structure of gene body are also significant (Stenvinkel et al., 2007). Special attention has been paid to genetic and epigenetic studies in the scope of biomarkers of drug response and personalized treatment, also in nephrology.

Therefore, the aim of this study was to examine genetic and epigenetic mechanisms of previously report-

e-mail: katarzyna.zaorska@gmail.com

Abbreviations: AP-1, Activator protein-1; bp, base pair; Dnmt, DNA methyltransferase; EDTA, Ethylenediaminetetraacetic acid; F, Forward; GCs, Glucocorticosteroids; IFN-gamma, Interferon-gamma; INS, Idiopathic Nephrotic Syndrome; ISKDC, International Study of Kidney Disease in Children; MAF, Minor Allele Frequency; MSP, Methylation Specific PCR; NS, Nephrotic Syndrome; nt, nucleotide; PBMC, Peripheral Blood Mononuclear Cell; PCR, Polymerase Chain Reaction; QMSP, Quantitative Methylation-Specific PCR; R, Reverse; RA, Rheumatoid Arthritis; SNP, Single Nucleotide Polymorphism; SOCS, Suppressor of Cytokine Signaling; Sp1, Specificity protein 1; SR, Steroid Resistant; SS, Steroid Sensitive; STAT, Signal Transducer and Activator of Transcription; Th, T helper cell; UTR, Untranslated Region 
ed SOCS3 and SOCS5 up-regulation in steroid resistant children with INS. We conducted SNP genotyping in promoters of SOCS 3 and SOCS 5 and estimated the methylation status of their $\mathrm{CpG}$ islands.

\section{SUBJECTS AND METHODS}

Study Subjects. We recruited 76 Caucasian children (39 males (51.3\%) and 37 females (48.7\%)) diagnosed with NS for our study. All patients were followed up at the Clinic of Cardiology and Nephrology, University of Medical Sciences in Poznan, Poznań, Poland. The age of patients ranged from 3 months to 16 years (mean 3.9 \pm S.D. 3.4 years). All patients were treated according to standard ISKDC (International Study of Kidney Disease in Children) regimen for the first NS episode, as reported previously (Ostalska-Nowicka et al., 2011). After administration of drugs, all patients were categorized into two subgroups, depending on the results of initial treatment: primary steroid resistant (SR) subgroup (40 patients: 23 males (57.5\%) and 17 females (42.5\%)) and primary steroid sensitive (SS) subgroup (36 patients: 16 males $(44.4 \%)$ and 20 females $(55.6 \%))$. Steroid sensitivity and resistance were defined according to the ISKDC standards (Banaszak \& Banaszak, 2012).

33 healthy children (20 males $(60.6 \%)$ and 13 females $(39.4 \%)$ ) without renal diseases were recruited as the control group and were sex, age and ethnically matched.

Analysis protocol was approved by the Ethics Com-

Table 1. Single nucleotide polymorphisms for SOCS3 and SOCS5 analyzed in this study. MAF, minor allele frequency; *when available

\begin{tabular}{|c|c|c|c|c|c|}
\hline & Name of variation & MAF * & Location & Base pair position & nt change \\
\hline \multicolumn{6}{|c|}{ SOCS3 } \\
\hline 1 & rs111033850 & 0.06 & 5'UTR & Chr17:78360132 & $\mathrm{T}>\mathrm{C}$ \\
\hline 2 & rs12953258 & 0.18 & exon 1 (UTR) & Chr17:78360015 & $C>A$ \\
\hline 3 & rs192803725 & 0.01 & exon 1 (UTR) & Chr17:78359894 & $C>A$ \\
\hline 4 & rs116303707 & $<0.01$ & intron 1 & Chr17:78359604 & $C>G$ \\
\hline 5 & rs148699063 & $<0.01$ & intron 1 & Chr17:78359431 & $C>A$ \\
\hline 6 & rs113849007 & & intron 1 & Chr17:78359325 & $C>G$ \\
\hline \multicolumn{6}{|c|}{ SOCS5 } \\
\hline 1 & rs41452946 & 0.01 & 5'UTR & Chr2:46698240 & $\mathrm{C}>\mathrm{T}$ \\
\hline 2 & rs35750425 & 0.07 & 5'UTR & Chr2:46698373 & $\mathrm{G}>\mathrm{T}$ \\
\hline 3 & rs13386416 & & 5'UTR & Chr2:46698433 & $A>T$ \\
\hline 4 & rs190344190 & $<0.01$ & 5'UTR & Chr2:46698486 & $C>A$ \\
\hline 5 & rs376147440 & & 5'UTR & Chr2:46698531 & $\mathrm{G}>\mathrm{C}$ \\
\hline 6 & rs41501846 & 0.01 & 5'UTR & Chr2:46698533 & $\mathrm{T}>\mathrm{C}$ \\
\hline 7 & rs4952842 & 0.22 & 5'UTR & Chr2:46698591 & $C>A$ \\
\hline 8 & rs185459620 & $<0.01$ & 5'UTR & Chr2:46698608 & $\mathrm{G}>\mathrm{A}$ \\
\hline 9 & rs41389052 & 0.07 & 5'UTR & Chr2:46698642 & $A>C$ \\
\hline 10 & rs3829835 & 0.23 & 5'UTR & Chr2:46698650 & $\mathrm{C}>\mathrm{T}$ \\
\hline 11 & rs189872419 & $<0.01$ & 5'UTR & Chr2:46698671 & $\mathrm{T}>\mathrm{C}$ \\
\hline 12 & rs3814040 & & 5'UTR & Chr2:46698720 & $\mathrm{C}>\mathrm{T}$ \\
\hline 13 & rs41504048 & 0.01 & 5'UTR & Chr2:46698721 & $C>A$ \\
\hline 14 & rs77033967 & & 5'UTR & Chr2:46698726 & $\mathrm{C}>\mathrm{T}$ \\
\hline 15 & rs41417248 & & 5'UTR & Chr2:46698895 & $G>A$ \\
\hline 16 & rs3814039 & 0.29 & 5'UTR & Chr2:46698925 & $C>G$ \\
\hline 17 & rs13000826 & & exon 1 (UTR) & Chr2:46699007 & $\mathrm{C}>\mathrm{G}$ \\
\hline 18 & rs111677684 & & intron 1 & Chr2:46699283 & $\mathrm{T}>\mathrm{C}$ \\
\hline 19 & rs79753377 & $<0.01$ & intron 1 & Chr2:46758098 & $\mathrm{T}>\mathrm{C}$ \\
\hline 20 & rs41320649 & & intron 1 & Chr2:46758106 & $\mathrm{T}>\mathrm{A}$ \\
\hline 21 & rs34642457 & & intron 1 & Chr2: $46758168-46758169$ & $->C$ \\
\hline 22 & rs200381087 & & intron 1 & Chr2:46758338 & $C>G$ \\
\hline 23 & rs41428947 & 0.01 & intron 1 & Chr2:46758353 & $\mathrm{T}>\mathrm{C}$ \\
\hline 24 & rs41483445 & 0.04 & intron 1 & Chr2:46758405 & $\mathrm{G}>\mathrm{A}$ \\
\hline 25 & rs148852176 & $<0.01$ & intron 1 & Chr2:46758451 & $C>G$ \\
\hline 26 & rs369277165 & & intron 1 & Chr2:46758512 & $\mathrm{T}>\mathrm{G}$ \\
\hline 27 & rs372918921 & & exon 2 (UTR) & Chr2:46758527 & $A>G$ \\
\hline
\end{tabular}

mittee of Poznan

University of Medical Sciences and the recruitment of patients was performed after their parents gave signed consents.

SNPs genotyping. Genomic DNA was extracted from the whole blood, collected in EDTA vials during hospitalization of patients, before the first steroid dose. DNA extraction was performed using Quick Blood DNA Purification Kit (EURx), according to the manufacturer's protocol.

To determine the functional promoter regions of SOCS3 (GeneBank:9021) and SOCS5 (GeneBank:9655) for our analysis we used Cister (Cis-element cluster finder) software (http://zlab. bu.edu/ mfrith / cister.shtml) and the literature review (Paul et al., 2000; He et al., 2003a; Ehlting et al., 2005). 6 single nucleotide polymorphisms for SOCS3 and 27 SNPs for SOCS5 were genotyped. All SNPs were assessed by the Ensembl database (http://www. ensembl.org) and are listed in Table 1. We performed Sanger sequencing using primers designed with Primer 3. Table 2 shows primers used in PCR analysis for amplification of 
Table2. Primer sequences for analysis of SOCS3 and SOCS5 polymorphisms.

F, Forward; R, Reverse. Amplified region estimated as nucleotide number in reference to ATG triplet.

\begin{tabular}{|c|c|c|}
\hline Region & Sequences & Annealing temp./elongation \\
\hline \multicolumn{3}{|l|}{ SOCS3 } \\
\hline \multirow{2}{*}{$-1397 /-1054$} & F: 5'-CAGGTCGGCCTCCTAGAACT-3' & \multirow{2}{*}{$59^{\circ} \mathrm{C} / 30 \mathrm{~s}$} \\
\hline & R: 5'-CCGGCCTTCTTGTAATGTTT-3' & \\
\hline \multirow{2}{*}{$-1201 /-855$} & F: 5'-CTCTCGTCGCGCTITGTCT-3' & \multirow{2}{*}{$59^{\circ} \mathrm{C} / 30 \mathrm{~s}$} \\
\hline & R: 5'-GGGAGGGGACCAGGAGAG-3' & \\
\hline \multirow{2}{*}{$-977 /-428$} & F: 5'-CGACTTGGACTCCCTGCTC-3' & \multirow{2}{*}{$61^{\circ} \mathrm{C} / 60 \mathrm{~s}$} \\
\hline & R: 5'-GTGTGGACGGAGGGAGAAAC-3' & \\
\hline \multirow{2}{*}{$-521 /+23$} & F: 5'-ATCCCAGGTTCCCGGAATAC-3' & \multirow{2}{*}{$60^{\circ} \mathrm{C} / 60 \mathrm{~s}$} \\
\hline & R: 5'-GGAAACTTGCTGTGGGTGAC-3' & \\
\hline \multirow{2}{*}{$-361 /+23$} & F: 5'-GCCACACTCCTGGAGACCTA-3' & \multirow{2}{*}{$60^{\circ} \mathrm{C} / 60 \mathrm{~s}$} \\
\hline & F: 5'-GGAAACTTGCTGTGGGTGAC-3' & \\
\hline \multicolumn{3}{|l|}{ SOCS5 } \\
\hline \multirow{2}{*}{$-60351 /-59851$} & F: 5'-GGTACGTTTGTGAACGACGA-3' & \multirow{2}{*}{$60^{\circ} \mathrm{C} / 60 \mathrm{~s}$} \\
\hline & R: 5'-GAGAGGAAAGTGCTGAATGGA-3' & \\
\hline \multirow{2}{*}{$-60042 /-59481$} & F: 5'-CCCTCCGATTTGTGAGTCAT-3' & \multirow{2}{*}{$60^{\circ} \mathrm{C} / 60 \mathrm{~s}$} \\
\hline & R: 5'-GTAGGTGAAGGCCGAAGGAG-3' & \\
\hline \multirow{2}{*}{$-59598 /-59150$} & F: 5'-AGCTGCCAGACTCCAAAATG-3' & \multirow{2}{*}{$59^{\circ} \mathrm{C} / 60 \mathrm{~s}$} \\
\hline & R: 5'-GTCACCGACAGGGCGAGT-3' & \\
\hline \multirow{2}{*}{$-471 /+81$} & $\begin{array}{l}\text { F: 5'-GGGAAGATTGCTACTAATGA- } \\
\text { AAGG-3' }\end{array}$ & \multirow{2}{*}{$60^{\circ} \mathrm{C} / 60 \mathrm{~s}$} \\
\hline & R: 5'-ACTACGGCTTCCTCCCTCAT-3' & \\
\hline
\end{tabular}

2008; Zhang et al., 2013), methylation status may differ in the same sample depending on the selection of $\mathrm{CpG}$ island region, that is why we selected 3 representative regions for SOCS3 and 1 region for SOCS5. MSP primers that recognized methylated and unmethylated sequences within SOCS3 and SOCS 5 CpG islands are listed in Table 3. SOCS3.2 primers were adopted from Ghattas et al. (2013). The reaction was performed in a final volume of $12.5 \mu \mathrm{l}$, containing $1 \mu \mathrm{l}$ of bisulfite-treated DNA, $200 \mu \mathrm{M}$ of dNTPs, $0.5 \mu \mathrm{M}$ of each primer, 1x PCR buffer and 1U of FastStart DNA polymerase (Roche). All amplifications were performed in Veriti 96 Well Thermal Cycler (Applied Biosystems) under conditions: initial denaturation at $95^{\circ} \mathrm{C}$ for $4 \mathrm{~min}$, followed by 35 cycles of $95^{\circ} \mathrm{C}$ for $30 \mathrm{~s}$, specific annealing temperature for $30 \mathrm{~s}, 72^{\circ} \mathrm{C}$ for $1 \mathrm{~min}$, and a final extension at $72^{\circ} \mathrm{C}$ for $7 \mathrm{~min} 10 \mu \mathrm{l}$ of MSP-PCR product was loaded on $2.5 \%$ agarose gel with ethidium bromide used for visualization after electrophoresis. We used Jurkat Genomic DNA and CpG Methylated Jurkat Genomic DNA (Thermo Scientific) as positive controls for unmethylated and methylated DNA, respectively.

overlapping regions. The reaction mastermix contained 30-60 ng of DNA, $200 \mu \mathrm{M}$ of dNTPs, $0.5 \mu \mathrm{M}$ of each primer, 1x PCR buffer and 1U of FastStart DNA polymerase (Roche) in a final volume of $12.5 \mu \mathrm{l}$. The reactions were performed in Veriti 96 Well Thermal Cycler (Applied Biosystems) and the conditions were: $95^{\circ} \mathrm{C}$ for 4 min, followed by 35 cycles of $95^{\circ} \mathrm{C}$ for $30 \mathrm{~s}$, specific annealing temperature for $1 \mathrm{~min}, 72^{\circ} \mathrm{C}$ for $1 \mathrm{~min}$, and a final extension at $72^{\circ} \mathrm{C}$ for $7 \mathrm{~min}$. PCR products were purified using 96-well membrane plates (Millipore) and used as templates in sequencing-PCR. The latter reaction was performed with only one primer (Forward or Reverse) and products were purified using EDTA and ethanol precipitation, according to the Life Technologies protocol. Formamide (Applied Biosystems) was used for denaturation of samples and then they were separated by capillary electrophsoresis using ABI Prism 3130 Genetic Analyzer (Applied Biosystems).

Methylation status of SOCS3 and SOCS5 CpG islands. $1 \mu \mathrm{g}$ of genomic DNA was used for bisulfite conversion using commercially available EZ DNA Methylation Kit (Zymo Research). Methylation status of SOCS3 and SOCS 5 CpG islands was investigated by methylation-specific polymerase chain reaction (MSP-PCR) as previously reported (Wojdacz \& Dobrovic, 2007). We used Methyl Primer Express v1.0 software to design MSP primers that specifically recognized the methylated and unmethylated sequence. A graphical overview of SOCS3 and SOCS5 is shown in Fig. 1. As previously described (Niwa et al., 2005; Fernández-Mercado et al.,
Additionally, we performed quantitative methylation-specific PCR (QMSP) to determine the relative methylation level. The higher the number of $\mathrm{CpG}$ sites within the amplicon, the higher the $\mathrm{Ct}$ values and the difference of melting temperature between highly methylated and unmethylated DNA template (Wojdacz \& Dobrovic, 2007). Here, we analyzed SOCS3.1 and SOCS3.2 regions for evaluation of $\mathrm{Ct}$, as differences in the methylation status were shown for these regions (see: Results). QMSP was carried out using primers specific both for methylated and unmethylated sequences. The reaction was performed in a final volume of $20 \mu \mathrm{l}$, containing $4 \mu \mathrm{l}$ of $5 \mathrm{x}$ Hot FirePol EvaGreen HRM Mix (Solis BioDyne), $0.25 \mu \mathrm{M}$ of each primer and $1 \mu \mathrm{l}$ of bisulfite-treated DNA. The amplification was carried out in 7900HT Fast Real-Time PCR System (Applied Biosystems) under conditions: initial denaturation at $95^{\circ} \mathrm{C}$ for $15 \mathrm{~min}$, followed by 40 cycles of $95^{\circ} \mathrm{C}$ for $15 \mathrm{~s}, 60^{\circ} \mathrm{C}$ for $20 \mathrm{~s}$ and $72^{\circ} \mathrm{C}$ for $20 \mathrm{~s}$.

Statistical analyses. Sequencing Analysis v5.2 was used to collect genotyping data. Genotype and allele frequencies for analyzed SNPs in SOCS3 3 and SOCS5 were tested by the chi-square test for deviation from HardyWeinberg and to compare gender variable, while the Fisher's exact test was used to investigate differences in genotype and allele frequencies between study groups. Comparisons between SR and SS patients and between NS patients (defined as SS and SR patients altogether) and controls were performed. $P$-values $\leq 0.05$ were considered statistically significant. 
Table 3. MS-PCR primer sequences for analysis of SOCS3 and SOCS5 CpG islands. M, methylated; U, Unmethylated; F, Forward; R, Reverse. Amplified region estimated as nucleotide number in reference to ATG triplet.

\begin{tabular}{|c|c|c|}
\hline CpG region & Sequences & Product size \\
\hline SOCS3.1 & MF: 5'-ATTATAAGAAGGTCGGTCGC-3' & 139 bp \\
\hline \multirow{3}{*}{$-1070 /-926$} & MR: 5'-CTAACTACGTACGAAACCGAA-3' & \\
\hline & UF: 5'-AATATTATAAGAAGGTTGGTTGT-3' & $145 \mathrm{bp}$ \\
\hline & UR: 5'-ACTAACTACATACAAAACCAAAAC-3' & \\
\hline SOCS3.2 & MF: 5'-GGAGATITTAGGTITCGGAATATTTC-3' & $142 \mathrm{bp}$ \\
\hline \multirow[t]{3}{*}{$-526 /-385$} & MR: 5'-CCCCCGAAACTACCTAAACGCCG-3' & \\
\hline & UF: 5'-GTTGGAGATITTAGGTTITTGGAATATाTा-3' & $151 \mathrm{bp}$ \\
\hline & UR: 5'-AAACCCCCAAAACTACCTAAACACCA-3' & \\
\hline SOCS3.3 & MF: 5'-TITITGATTCGCGATAGTTC-3' & $143 \mathrm{bp}$ \\
\hline \multirow[t]{3}{*}{$202 / 344$} & MR: 5'-AACACGAACTACGTACTCCG-3' & \\
\hline & UF: 5'-ATTITITGATTTGTGATAGTTT-3' & $146 \mathrm{bp}$ \\
\hline & UR: 5'-AACACAAACTACATACTCCAAAA-3' & \\
\hline SOCS5 & MF: 5'-ATGGTAGTTCGTAGAGCGC-3' & $112 \mathrm{bp}$ \\
\hline \multirow[t]{3}{*}{$-59566 /-59460$} & MR: 5'-CGAAATTCCTAACGACCAAT-3' & \\
\hline & UF: 5'-AAAATGGTAGTTTGTAGAGTGT-3' & 118 bp \\
\hline & UR: 5'-ACAAAATTCCTAACAACCAATCC-3' & \\
\hline
\end{tabular}

We used Fisher's exact test to evaluate the differences in methylation status between the study groups and $P$-values $\leq 0.05$ were considered statistically significant. The Wilcoxon test was used to assess the differences in methylation status between the groups. All statistical analyses were performed in the $\mathrm{R}$ language.

\section{RESULTS}

\section{SOCS3 and SOCS5 single nucleotide polymorphisms and LD analysis}

We screened $76 \mathrm{NS}$ patients and 33 controls for 6 SNPs in SOCS3 and 27 SNPs in SOCS5. All genotypes were in Hardy-Weinberg equilibrium. Figure 1 shows graphical overview of genotyped polymorphisms. Out of all 33 SNPs submitted in this study, 26 were homozy-

gous in all subjects and they were excluded from further statistical analyses. For 7 heterozygous SNPs (rs12953258 in SOCS3 and rs35750425, rs4952842, rs41389052, rs3829835, rs3814039, rs41483445 in SOCS5) genotype/ allele frequencies were calculated and compared. Genotype and allele frequencies and $\mathrm{p}$-values for heterozygous markers analyzed in the study are listed in supplementary Table 4 (at www.actabp.pl). There were no significant differences between study groups and between males and females in each group.

\section{Methylation status of SOCS3 and SOCS5 promoters}

MSP-PCR. The methylation-specific PCR results are shown in Table 5. All study subjects displayed positive methylation for SOCS3.1 promoter region. In the NS group, $5.3 \%(n=4)$ showed full unmethylation (positive reaction only with the unmethylated primers), while $94.7 \% \quad(\mathrm{n}=72)$ showed partial methylation (positive for both methylated and unmethylated primers). In the SR group, $5 \%(n=2)$ of the samples were fully unmethylated and 95\% $(\mathrm{n}=38)$ showed partial methylation. In the SS group, $5.6 \%(n=2)$ of the samples were fully unmethylated and $94.4 \%(n=34)$ showed partial methylation. $3 \%(n=1)$ of the samples in the controls were unmethylated, while 97\% $(n=32)$ showed partial methylation. The differences in methylation status of SOCS3.1 promoter region were not statistically significant between the study groups $(p=0.6132$ for NS patients $v s$. controls; $p=0.9138$ for SR vs. SS patients).

A positive methylation for SOCS3.2 promoter region was also detected in all study subjects. In the NS group, $51.3 \%(n=39)$ was fully unmethylated and $48.7 \%$ $(n=37)$ showed partial methylation. However, there was a strong significant difference between NS subgroups $(p<0.0001)$. In the SR group, $82.5 \%(\mathrm{n}=33)$ of patients showed fully unmethylated region 2 , while $17.7 \%(n=7)$ showed partial methylation. On the contrary, in the SS group, only $16.7 \%(n=6)$ was fully unmethylated, while $83.3 \%(\mathrm{n}=30)$ showed partial methylation. In controls,

(a)

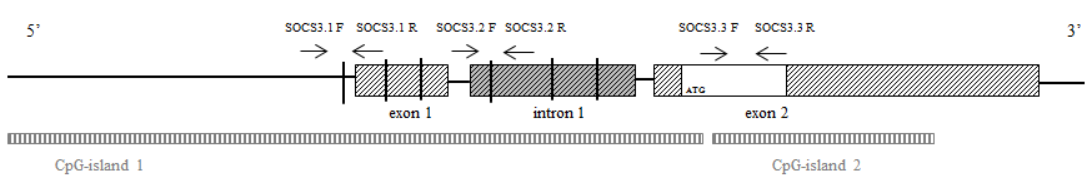

(b)

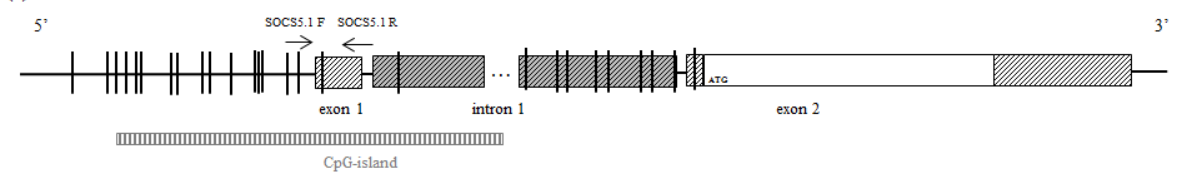

Figure 1. Schematic diagram of SOCS3 and SOCS5 genes analyzed in this study.

Cross-hatched white rectangles represent untranslated regions, cross-hatched grey rectangles - introns and white rectangles - translated regions of exons. The translation start at the ATG triplet is marked. Vertical lines indicate polymorphisms analyzed in this study. CpG island extension is indicated as tripped grey rectangles below the diagrams. Gene regions amplified for methylation analysis are indicated by arrows, representing forward and reverse primers. (a) SOCS3; (b) SOCS5.
$6.1 \%(n=2)$ of the samples were fully unmethylated and $93.9 \% \quad(n=31)$ were partially methylated. The methylation status of SOCS3.2 region was not significantly different between the controls and SS patients $(p=0.1861)$, however there was a significant difference between SR and SS group $(p<0.0001)$ and between NS patients and controls $(p=0.0003)$.

For SOCS3.3 promoter region $100 \%$ of the samples of all study groups showed full methylation, while for SOCS5 promoter region a fully unmethylated 


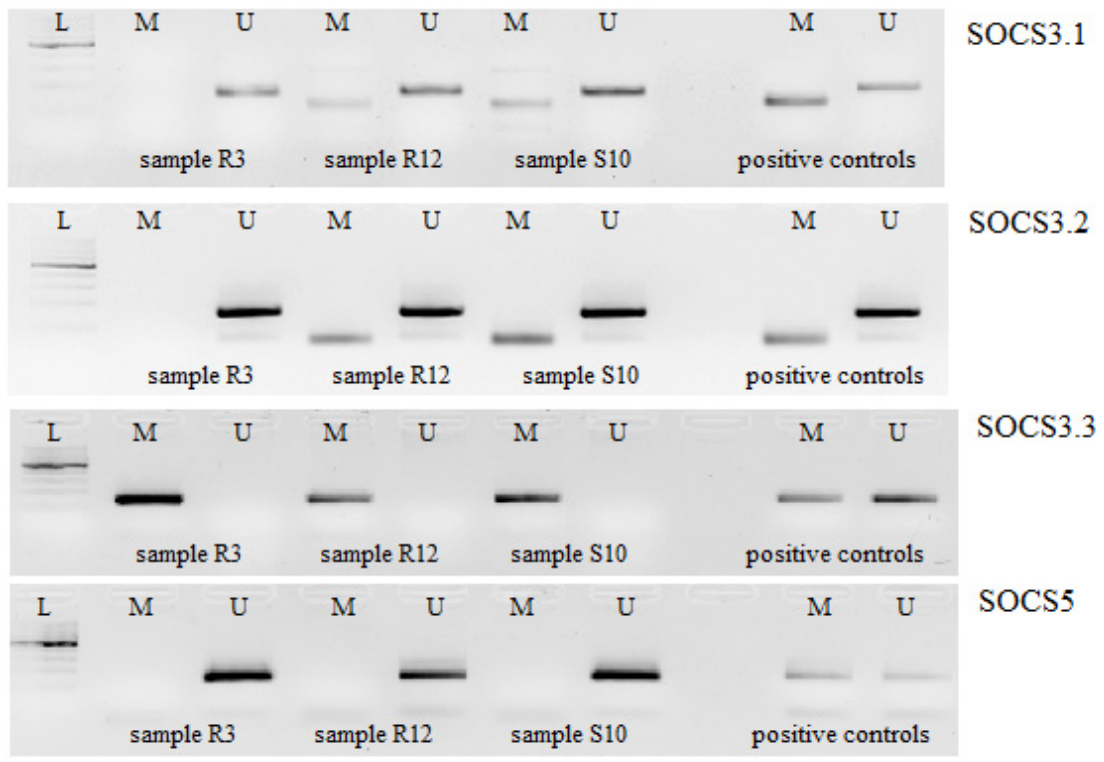

Figure 2. Representative data for gel-based methylation status of SOCS3 promoter (regions 1, 2 and 3) and of SOCS5 promoter (region 1).

$\mathrm{M}$, methylated DNA; U, unmethylated DNA; $\mathrm{L}, 100-1000$ bp DNA ladder; positive $\mathrm{M}$ and $\mathrm{U}$ controls (universal methylated and unmethylated DNA). Illustrative samples of two steroid resistant patients (R3 and R12) and one steroid sensitive patient (S10) are shown for visualization of methylation status of all promoter regions analyzed in this study. (a) region1 of SOCS3 promoter; (b) region2 of SOCS3 promoter; (c) region3 of SOCS3 promoter; (d) region1 of SOCS5 promoter.

$(100 \%)$ pattern was observed. Figure 2 shows representative results of methylation status of SOCS3.1, SOCS3.2, SOCS3.3 and SOCS5.1 promoter regions. There were no differences in methylation pattern of any region of SOCS3 and SOCS5 promoters in reference to gender in the study groups (data not shown).

Table 5. Gel-based methylation status of SOCS3 and SOCS5 promoter in NS patients and controls. $-/ U$, full unmethylation (positive reaction only with the unmethylated primers); $M / U$, partial methylation (positive for both methylated and unmethylated primers); $M / /-$, full methylation (positive reaction only for methylated primers); The $P$-value represents fisher's exact test; ${ }^{* * *}$ statistically significant at $p \leq 0.001$.

\begin{tabular}{|c|c|c|c|c|c|c|}
\hline Gene/Region & & M/- & $M / U$ & $-/ U$ & $P$-value & \\
\hline \multicolumn{7}{|l|}{ SOCS3/ } \\
\hline \multirow[t]{4}{*}{ SOCS3.1 } & NS $n=76$ & $0(0 \%)$ & $72(94.7 \%)$ & $4(5.3 \%)$ & NS vs. C & 0.6132 \\
\hline & $S R n=40$ & $0(0 \%)$ & $38(95.0 \%)$ & $2(5.0 \%)$ & SR vs. SS & 0.9138 \\
\hline & SS $n=36$ & $0(0 \%)$ & 34 (94.4\%) & $2(5.6 \%)$ & SS vs. C & 0.6126 \\
\hline & $C n=33$ & $0(0 \%)$ & 32 (97.0\%) & 1 (3.0\%) & SR vs. C & 0.6762 \\
\hline \multirow[t]{4}{*}{ SOCS3.2 } & NS $n=76$ & $0(0 \%)$ & 37 (48.7\%) & 39 (51.3\%) & NS vs. C & $0.0003^{* * *}$ \\
\hline & $S R n=40$ & $0(0 \%)$ & 7 (17.5\%) & 33 (82.5\%) & SR vs. SS & $<0.0001^{* * *}$ \\
\hline & SS $n=36$ & $0(0 \%)$ & 30 (83.3\%) & $6(16.7 \%)$ & SS vs. C & 0.1861 \\
\hline & $C n=33$ & $0(0 \%)$ & 31 (93.9\%) & 2 (6.1\%) & SR vs. C & $<0.0001^{* * *}$ \\
\hline \multirow[t]{4}{*}{ SOCS3.3 } & NS $n=76$ & $76(100 \%)$ & $0(0 \%)$ & $0(0 \%)$ & & \\
\hline & $S R n=40$ & $40(100 \%)$ & $0(0 \%)$ & $0(0 \%)$ & & \\
\hline & SS $n=36$ & $36(100 \%)$ & $0(0 \%)$ & $0(0 \%)$ & & \\
\hline & $C n=33$ & $33(100 \%)$ & $0(0 \%)$ & $0(0 \%)$ & & \\
\hline SOCS5/ & NS $n=76$ & $0(0 \%)$ & $0(0 \%)$ & $76(100 \%)$ & & \\
\hline \multirow[t]{3}{*}{ SOCS5.1 } & $S R n=40$ & $0(0 \%)$ & $0(0 \%)$ & 40 (100\%) & & \\
\hline & SS $n=36$ & $0(0 \%)$ & $0(0 \%)$ & $36(100 \%)$ & & \\
\hline & $C n=33$ & $0(0 \%)$ & $0(0 \%)$ & 33 (100\%) & & \\
\hline
\end{tabular}

QMSP. Additionally, we analyzed a relative CpG methylation level calculated as the Ct value for SOCS3.1 and SOCS3.3 promoter regions. We performed Wilcoxon rank sum test with continuity correction as more efficient than the t-test for analysis of both regions (Fig. 3). There were no significant differences in methylation level of SOCS3.1 region between analyzed groups (Fig. 3c). Surprisingly, there was a significant difference between SR group and controls $(p=1.013 \mathrm{e}-10)$, as well as between SS group and controls $\quad(p=0.001758)$, while no such observation was made for SR and SS comparison $\quad(p=0.8027)$ (Fig. 3d).

\section{DISCUSSION}

The scope of this study was to investigate the genetic and epigenetic status of the promoter regions of SOCS 3 and SOCS5 genes and to correlate differences between genotype distribution and/or methylation status to steroid sensitivity or resistance in the course of NS in children. In a previous study (Ostalska-Nowicka et al., 2011), we had demonstrated aberrant expression levels of SOCS3 and SOCS5 in monocytes and $\mathrm{T}$ cells, 

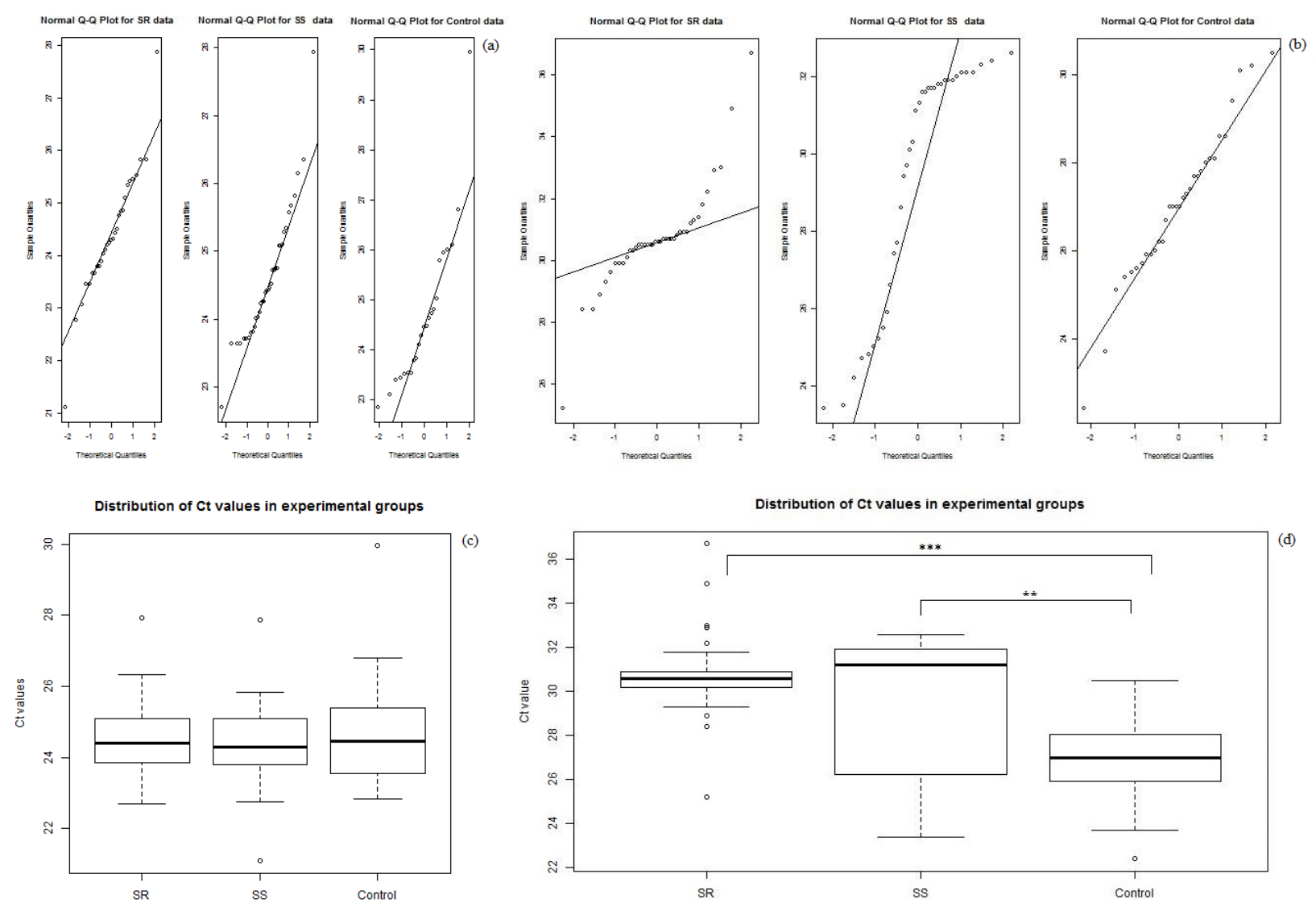

Figure 3. Relative methylation levels of SOCS3 promoter regions 1 and 2.

The results of the Wilcoxon ran sum test shown as Q-plots presenting non-normal distribution in SR, SS and control group for SOCS3.1 region (a) and for SOCS3.2 region (b). Distribution of Ct values shown as box-plots for SR, SS and control group for SOCS3.1 region (c) and for SOCS3.2 region (d). Significance at $p<0.01^{* *}, p<0.001^{* * *}$.

respectively, in NS patients after administration of steroids. The analysis of single nucleotide polymorphisms in coding regions of both SOCS genes did not reveal any significant differences between steroid sensitive and resistant children (data not shown). Here we demonstrate that SOCS3 expression might be epigenetically regulated in peripheral blood cells of NS patients due to a high level of demethylation of SOCS3 promoter region, which corresponded to SOCS3 up-regulation in steroid resistant NS children.

The hypermethylation of promoter of suppressor genes, including SOCS factors, is a well known mechanism of gene silencing in many diseases ( $\mathrm{He}$ et al., 2003b; Stenvinkel et al., 2007; Sobti et al., 2011; Wilop et al., 2011). Recently, more interest has been drawn to the role of promoter hypomethylation and its deregulative influence on genetic instability and promoting forced or prolonged gene expression in tumorigenesis and various immunological disturbances (Mi \& Zeng, 2008). CpG methylation occurs to be an integral component of transcription and methylation-demethylation alteration is an active, rapid and cyclic process (Metivier et al., 2008; Kobayashi et al., 2012). Moreover, epigenetic patterns could not only distinguish between types of malignancies serving as specific markers, but could also alter drug sensitivity and affect drug resistance (Teodoridis et al., 2004; Wojdacz \& Dobrovic, 2007; Fernández-Mercado et al., 2008; Ghattas, 2013).
It is still argued whether steroid resistance during the course of NS is an acquired mechanism resulting from rapidly changing inner immunity or a primary disease that results in increased cytokine signaling restricted to the kidney area, despite administration of anti-inflammatory drugs (Kam et al., 1993). Circulating cytokines themselves have been shown to induce steroid resistance, observed in lymphocytes and monocytes (Barnes, 1998; Bantel et al., 2002; Camici, 2007). Others (Stenvinkel et al., 2007; Delcuve, 2009; Hodge et al., 2011) have demonstrated that pro-inflammatory cytokines and chronic inflammation could influence DNA methylation mainly through the increased DNA methyltransferase (Dnmt) expression and activity. Ghattas et al. (Ghattas et al., 2013) indicated an altered methylation pattern of IFN-gamma, SOCS1 and SOCS3 promoters in patients with chronic kidney disease in comparison with healthy controls. Gene expression levels also correlated with a severity of inflammation and progression to end stage renal disease. In this study, SOCS3 promoter was significantly hypomethylated in SR patients in comparison with SS patients and healthy controls. Interestingly, in our previous study SOCS3 was up-regulated in all NS patients before the first dose of steroids and only in steroid sensitive patients it was down-regulated to the level compared with controls, after administration of the drugs (Ostalska-Nowicka et al., 2011). It is known that GCs exert their anti-inflammatory action mainly 
through the negative regulation of $\mathrm{T}$ helper type 1 cells and modification of the immune response (Ramírez et al., 1996; Berkley et al., 2013). It is also well documented that active methylation/demethylation processes regulate activation and repression of genes responsible for CD4+ $\mathrm{T}$ cell differentiation and maintenance (Teitell \& Richardson, 2003; Wilson et al., 2005; Kino, 2007; Komatsuda et al., 2008; Chaoran, 2014). Richardson (2003) showed that defective DNA methylation of Th cells resulted in diverse immune reactivity in vitro and in vivo in mice, resembling that of $\mathrm{Th}_{2}-$ and $\mathrm{Th}_{1}$-type autoimmune diseases. Discordant methylation can therefore result in an excessive $\mathrm{Th}_{1}$ or $\mathrm{Th}_{2}$ polarization in SR and SS patients (respectively) during the course of NS, as well as in constant changes of immune response during remissions and relapses (Komatsuda et al., 2008). Also, T cells from patients with rheumatoid arthritis have been reported to have hypomethylated DNA, but in contrast to lupus patients, $\mathrm{T}$ cells from RA patients demonstrated normal Dnmt1 expression levels (Richardson, 2003). Dnmt expression analysis was beyond the scope of this study, however, its role in steroid resistance in NS needs further research.

Out of three analyzed SOCS3 promoter regions, only one (SOCS3.2) was significantly aberrantly methylated between SR and SS patients in this study (Table 4). Interestingly, the MSP method showed no statistical differences in methylation status of SOCS3.2 region between SS and control subjects, while using QMSP we were able to distinguish methylation levels between those groups. However, MSP indicates an overall pattern of methylation characterized by the presence or absence of any methylated CpG sites within a sequence, while the QMSP method is a relative quantification of promoter methylation, dependent on precise number of $\mathrm{CpGs}$ altering specific Ct value. Moreover, the relative methylation levels for SS and SR patients were comparable $(p=0.8027)$. However, it should be emphasized that the high Ct values in SR group most probably resulted from artifacts, as $82.5 \%$ of SR patients exhibited positive reaction only for unmethylated sequence (Table 5). Therefore, the high $\mathrm{Ct}$ values in SS group indicated a relatively high methylation level, as $83.3 \%$ of SS patients showed methylation-positive pattern in MSP (Table 5). The level of methylated $\mathrm{CpG}$ sites in SS patients was statistically higher than in the healthy controls, although there were no differences in SOCS3 expression levels (Ostalska-Nowicka et al., 2011). It may not be excluded that different methylation levels of SOCS3.2 region in SR and SS groups may be due to a distinct mechanism, which implies the steroid sensitive and steroid resistant nephrotic syndrome to be independent diseases, demonstrating different mechanisms underlying the inflammatory process and action of GCs. It seems likely that the primary and acquired steroid resistance could also result from different immune cell activities. Unfortunately, we were not able to examine DNA methylation status in NS patients after the GC treatment. Nevertheless, distinct methylation pattern for SOCS3.2 promoter region between steroid sensitive and resistant NS patients strongly suggests different mechanisms of regulation of SOCS 3 expression in both groups and should be taken under consideration when deciding on proper patient treatment.

When evaluating the methylation status, it is recommended to select primers that amplify a particular region of interest (Niwa et al., 2005; Fernández-Mercado et al., 2008; Zhang et al., 2013). Surprisingly, in our study, no transcription factors known for SOCS3 appear to bind to promoter region SOCS3.2, while several, including
AP-1, STAT1, STAT3 and Sp1 have been shown to bind to region SOCS3.1, which showed no significant differences in methylation status between the groups. Apart from promoter methylation, point mutations and polymorphisms also work together to regulate gene transcription. Single nucleotide change might create a novel $\mathrm{CpG}$ site or influence binding of transcription factors (Gluckman et al., 2009). Several studies have demonstrated SOCS activation in a STAT-independent manner, by recruiting other signaling pathways than Jak/Stat (Paul et al., 2000; He et al., 2003a; Ehlting et al., 2005; Barclay et al., 2007; Yarwood et al., 2008). In this study, no heterozygous SNP was encompassed by the regions amplified for methylation analysis and allele/genotype distribution of SOCS3 and SOCS5 variants did not differ between the groups.

SOCS5.1 promoter region was completely unmethylated in all subjects in this study. In our previous study (Ostalska-Nowicka et al., 2011), there was a significantly higher SOCS5 expression level in SR, but not in SS patients, suggesting an unfavorable outcome with $\mathrm{Th}_{1}$ phenotype for SR patients. Interestingly, Zhang et al. (2013) demonstrated that changes in gene expression level do not have to accompany its aberrant methylation. Thus, it is unlikely for SOCS5 gene to be epigenetically regulated in peripheral blood cells in NS patients and we suppose that other mechanism could be responsible either for up-regulation of this gene in SR patients, or an unknown protective mechanism appears to down-regulate SOCS5 in PBMCs from SS patients and healthy controls.

Our study has some technical limitations. It would be also recommended to determine if the aberrant SOCS3 methylation is Dnmt-dependent. Nevertheless, here we describe an epigenetic mechanism of SOCS3 upregulation in steroid resistant children with nephrotic syndrome, which strongly seems to be regulated by the inflammation process itself, rather than an acquired immune reaction dependent on glucocorticoid action. It requires further studies, though it could be potentially used as an early predictive marker for steroid resistance in NS patients.

\section{Acknowledgements}

This study was supported by the Poznan University of Medical Sciences grant for Young Scientists No. 502-1402229373-09513, in the field of the material collection and all molecular analyses.

The authors declare that they have no competing interests. The authors also declare that the results presented in this paper have not been published previously in whole or in part, except in an abstract format.

\section{REFERENCES}

Bagga A, Mantan M (2005) Nephrotic syndrome in children. Indian J Med Res 122: 13-28. http://www.ncbi.nlm.nih.gov/pubmed/16106086.

Banaszak B, Banaszak P (2012) The increasing incidence of initial steroid resistance in childhood nephrotic syndrome. Pediatr Nephrol 27: 927-932. http://www.ncbi.nlm.nih.gov/pubmed/22231438

Bantel H, Schmitz ML, Raible A, Gregor M, Schulze-Osthoff K (2002) Critical role of NF-kappaB and stress-activated protein kinases in steroid unresponsiveness. Faseb J 16: 1832-1834. http://www.ncbi. nlm.nih.gov/pubmed/12223450.

Barclay JL, Anderson ST, Waters JW, Curlewis JD (2007) Characterization of the SOCS3 promoter response to prostaglandin E2 in T47D cells. Mol Endocrinol 21: 2516-2528. http://www.ncbi.nlm.nih.gov/ pubmed/17636039.

Barnes PJ (1998) Anti-inflammatory actions of glucocorticoids: molecular mechanisms. Clin Sci (Lond) 94: 557-572. http://www.ncbi.nlm. nih.gov/pubmed/9854452. 
Berkley AM, Hendricks DW, Simmons KB, Fink PJ (2013) Recent thymic emigrants and mature naive T cells exhibit differential DNA methylation at key cytokine loci. J Immun 190: 6180-6186. http:// www.ncbi.nlm.nih.gov/pmc/articles/PMC3679312/.

Camici M (2007) The nephrotic syndrome is an immunoinflammatory disorder. Med Hypotheses 68: 900-905. http://www.ncbi.nlm.nih.gov/ pubmed/17184932.

Chaoran L (2014) MicroRNA and epigenetic controls of CD4+ T cells' activation, differentiation and maintenance. http://hdl.handle. net $/ 10161 / 8639$.

Delcuve GP, Rastegar M, Davie JR (2009) Epigenetic control. J Cell Physiol 219: 243-250. http://www.ncbi.nlm.nih.gov/pubmed/19127539.

Ehlting C, Haussinger D, Bode JG (2005) Sp3 is involved in the regulation of SOCS3 gene expression. Biochem J 387: 737-745. http:// www.ncbi.nlm.nih.gov/pubmed/15554904.

Fernández-Mercado M, Cebrián V, Euba B et al. (2008) Methylation status of SOCS1 and SOCS3 in BCR-ABL negative and JAK2V617F negative chronic myeloproliferative neoplasms. Leuk Res 32: 16231640. http://www.ncbi.nlm.nih.gov/pubmed/18440067.

Ghattas M, El-shaaraway F, Mesbah N, Abo-Elmatty D (2013) The methylation profile of IFN-gamma, SOCS1 and SOCS3 promoter regions in end-stage renal disease. J Data Mining Genomics Proteomics 4: 144. http://www.omicsonline.org/the-methylationprofile-of-ifn-socs-and-socs-promoter-regions-in-endstage-renal-disease-2153-0602-4-144.php?aid=19603.

Gluckman PD, Hanson MA, Buklijas T, Low FM, Beedle AS (2009) Epigenetic mechanisms that underpin metabolic and cardiovascular diseases. Nat Rev Endocrinol 5: 401-408. http://www.ncbi.nlm.nih. gov/pubmed/19488075.

Gómez-Guerro C, López-Franco O, Sanjuán G, Hernández-Vargas P et al. (2004) Suppressors of cytokine signaling regulate Fc receptor signaling and cell activation during immune renal injury. I Immunol 172: 6969-6977. http://www.ncbi.nlm.nih.gov/pubmed/15153517.

He B, You L, Uematsu K et al. (2003a) Cloning and characterization of a functional promoter of the human SOCS-3 gene. Biochem Biopshys Res Commun 301: 386-391. http://www.ncbi.nlm.nih.gov/ pubmed/12565872.

He B, You L, Uematsu K, Zang K, Xu Z, Lee AY et al. (2003b) SOCS-3 is frequently silenced by hypermethylation and suppresses cell growth in human lung cancer. Proc Natl Acad Sci 100: 1413314138. http://www.ncbi.nlm.nih.gov/pmc/articles/PMC283558/.

Hinkes B, Vlangos C, Heeringa S et al. (2008) Specific podocin mutations correlate with age of onset in steroid-resistant nephrotic syndrome. J Am Soc Nephrol 19: 365-371. http://www.ncbi.nlm.nih. gov/pmc/articles/PMC2396749/.

Hodge DR, Xiao W, Clausen PA et al. (2011) Interleukin-6 regulation of the human DNA methyltransferase (HDNMT) gene in human erythroleukemia cells. J Biol Chem 276: 39508-39511. http://www. ncbi.nlm.nih.gov/pubmed/11551897.

Holt RCL, Webb NJA (2002) Management of nephrotic syndrome in childhood. Curr Pediatr 12: 551-560. http://dx.doi.org/10.1054/ cupe.2002.0348.

Huang Z, Wen Q, Zhou SF, Yu XQ (2008) Differential chemokine expression in tubular cells in response to urinary proteins from patients with nephrotic syndrome. Cytokine 42: 222-233. http://www. ncbi.nlm.nih.gov/pubmed/18362077.

Jafar T, Agrawal S, Mahdi AA, Sharma RK, Awasthi S, Agarwal GG (2011) Cytokine gene polymorphism in idiopathic nephrotic syndrome children. Ind J Clin Biochem 26: 296-302. http://www.ncbi. nlm.nih.gov/pmc/articles/PMC3162962/.

Kam JC, Szefler SJ, Surs W, Sher ER, Leung DY (1993) Combination of IL-2 and IL-4 reduces glucocorticoid receptor-binding affinity and $\mathrm{T}$ cell response to glucocorticoids. J Immunol 151: 3460-3466. http://www.ncbi.nlm.nih.gov/pubmed/8376786.

Kino T (2007) Tissue glucocorticoid sensitivity: beyond stochastic regulation on the diverse actions of glucocorticosteroids. Horm Metab Res 39: 420-424. http://www.ncbi.nlm.nih.gov/pubmed/17578758.

Kobayashi Y, Aizawa A, Takizawa T et al. (2012) DNA methylation changes between relapse and remission of minimal change nephrotic syndrome. Pediatr Nephrol 27: 2233-2241. http://www.ncbi.nlm. nih.gov/pubmed/22855301.

Komatsuda A, Wakui H, Iwamoto K, Harada M, Okumoto Y, Sawada K-i (2008) Gene expression profiling of peripheral blood mononu- clear cells from patients with minimal change nephrotic syndrome by cDNA microarrays. Am J Nephrol 28: 539-547. http://www.ncbi. nlm.nih.gov/pubmed/18219197.

Metivier R, Gallais R, Tiffoche C et al. (2008) Cyclical DNA methylation of a transcriptionally active promoter. Nature 452: 45-50. http://www.ncbi.nlm.nih.gov/pubmed/18322525.

Mi X, Zeng F (2008) Hypomethylation of interleukin-4 and -6 promoters in T cells from systemic lupus erythematosus patients. Acta Pharmacol Sin 29: 105-112. doi:10.1111/j.1745-7254.2008.00739.x.

Niwa Y, Kanda H, Shikauchi Y et al. (2005) Methylation silencing of SOCS-3 promotes cell growth and migration by enhancing JAK/STAT and Fak signaling in human hepatocellular carcinoma. Oncogene 24: 6406-6417. http://www.ncbi.nlm.nih.gov/pubmed/16007195.

Ostalska-Nowicka D, Śmiech M, Jaroniec M et al. (2011) SOCS3 and SOCS5 mRNA expressions may predict initial steroid response in nephrotic syndrome children. Folia Histochem Cytobiol 49: 719-728. http://www.ncbi.nlm.nih.gov/pubmed/22252769.

Paul C, Seiliz I, Thissen JP, Le Cam A (2000) Regulation of expression of the rat SOCS-3 gene in hepatocytes by growth hormone, interleukin-6 and glucocorticoids. Eur J Biochem 267: 5849-5857. http:// www.ncbi.nlm.nih.gov/pubmed/10998044.

Ramírez F, Fowell DJ, Puklavec M, Simmonds S, Mason D (1996) Glucocorticoids promote a Th2 cytokine response by CD4+ T cells in vitro. I Immuno 156: 2406-2412. http://www.ncbi.nlm.nih.gov/ pubmed/8786298.

Richardson BC (2003) DNA methylation and autoimmune disease. Clin Pathol 109: 72-79. http://www.ncbi.nlm.nih.gov/pubmed/14585278.

Sobti RC, Singh N, Hussain S et al. (2011) Aberrant promoter methylation and loss of Suppressor of cytokine signaling-1 gene expression in the development of uterine cervical carcinogenesis. Cell Oncol 34: 533-543. http://www.ncbi.nlm.nih.gov/pubmed/21935712.

Stenvinkel P, Karimi M, Johansson S et al. (2007) Impact of inflammation on epigenetic DNA methylation - a novel risk factor for cardiovascular disease? I Intern Med 261: 488-499. http://www.ncbi. nlm.nih.gov/pubmed/17444888.

Teitell M, Richardson B (2003) DNA methylation in the immune system. Clin Immunol 109: 2-5. http://www.ncbi.nlm.nih.gov/pubmed/14585270.

Teodoridis JM, Strathdee G, Brown R (2004) Epigenetic silencing mediated by $\mathrm{CpG}$ island methylation: potential as a therapeutic target and as a biomarker. Drug Resist Updat 7: 267-278. http://www.ncbi. nlm.nih.gov/pubmed/15533764.

Thomas DB (2009) Focal segmental glomerulosclerosis. Arch Pathol Lab Med 133: 217-223. http://www.archivesofpathology.org/doi/ pdf/10.1043/1543-2165-133.2.217.

Wilop S, van Gemmeren TB, Lentjes MHFM et al. (2011) Methylationassociated dysregulation of the suppressor of cytokine signaling-3 gene in multiple myeloma. Epigenetics 6: 1047-1052. http://www. ncbi.nlm.nih.gov/pubmed/21934357.

Wilson CB, Makar KW, Shnyreva M, Fitzpatrick DR (2005) DNA methylation and the expanding epigenetics of $\mathrm{T}$ cell lineage commitment. Semin Immunol 17: 105-119. http://www.ncbi.nlm.nih.gov/ pubmed/15737572.

Wojdacz TK, Dobrovic A (2007) Methylation-sensitive high resolution melting (MS-HRM): a new approach for sensitive and high-throughput assessment of methylation. Nucleic Acids Res 35: e41. http:// www.ncbi.nlm.nih.gov/pubmed/17289753.

Yarwood SJ, Borland G, Sands WA, Palmer TM (2008) Identification of CCAAT/enhancer-binding proteins as exchange protein activated by cAMP-activated transcription factors that mediate the induction of the SOCS-3 gene. J Biol Chem 283: 6843-6853. http://www.ncbi. nlm.nih.gov/pubmed/18195020.

Zhang L, Dai Y, Peng W, Lu J, Zhang Y, Wang L (2009) Genomewide analysis of histone $\mathrm{H} 3$ lysine 4 trimethylation in peripheral blood mononuclear cells of minimal change nephrotic syndrome patients. AM J Nephrol 30: 505-513. http://www.ncbi.nlm.nih.gov/ pubmed/19797895.

Zhang MY, Fung TK, Chen FY, Chim CS (2013) Methylation profiling of SOCS1, SOCS2, SOCS3, CISH and SHP1 in Philadelphianegative myeloproliferative neoplasm. J Cell Mol Med 17: 1282-1290. http://www.ncbi.nlm.nih.gov/pubmed/24131863. 